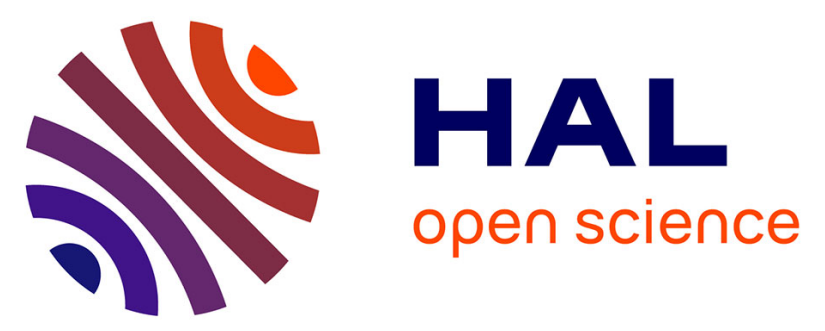

\title{
Predictive score for complete occlusion of intracranial aneurysms treated by flow-diverter stents using machine learning
}

\author{
Alexis Guédon, Cédric Thépenier, Eimad Shotar, Joseph Gabrieli, Bertrand \\ Mathon, Kévin Premat, Stéphanie Lenck, Vincent Degos, Nader Sourour, \\ Frédéric Clarençon
}

\section{To cite this version:}

Alexis Guédon, Cédric Thépenier, Eimad Shotar, Joseph Gabrieli, Bertrand Mathon, et al.. Predictive score for complete occlusion of intracranial aneurysms treated by flow-diverter stents using machine learning. Journal of Neurointerventional Surgery, 2021, 13 (4), pp.341-346. 10.1136/neurintsurg2020-016748 . hal-03196093

\section{HAL Id: hal-03196093 https://hal.sorbonne-universite.fr/hal-03196093}

Submitted on 12 Apr 2021

HAL is a multi-disciplinary open access archive for the deposit and dissemination of scientific research documents, whether they are published or not. The documents may come from teaching and research institutions in France or abroad, or from public or private research centers.
L'archive ouverte pluridisciplinaire HAL, est destinée au dépôt et à la diffusion de documents scientifiques de niveau recherche, publiés ou non, émanant des établissements d'enseignement et de recherche français ou étrangers, des laboratoires publics ou privés. 


\section{Predictive Score for Complete Occlusion of Intracranial Aneurysms Treated by Flow-}

Diverter Stents using Machine Learning

Original Research

Alexis Guédon, $\mathrm{MD}^{*}, 8,9$, Cédric Thepenier, $\mathrm{MD} \mathrm{PhD}^{3,4}$, Eimad Shotar, MD ${ }^{2}$, Joseph Gabrieli, $\mathrm{MD}^{5}$, Bertrand Mathon, MD ${ }^{1,6}$, Kévin Premat, MD ${ }^{1,2}$, Stéphanie Lenck, MD ${ }^{2}$, Vincent Degos, MD PhD ${ }^{1,7}$, Nader Sourour, MD ${ }^{2}$, Frédéric Clarençon, MD PhD ${ }^{1,2}$

${ }^{1}$ Sorbonne University, Paris, France

${ }^{2}$ Department of Neuroradiology, Pitié-Salpêtrière Hospital, Paris, France

${ }^{3}$ Department of Experimental Neuropathology, Institut Pasteur, Paris, France

${ }^{4}$ French Armed Forces Biomedical Research Institute (IRBA), Brétigny-sur-Orge, France

${ }^{5}$ Department of Neuroradiology, University Hospital of Padova, Padova, Italy

${ }^{6}$ Department of Neurosurgery, Pitié-Salpêtrière Hospital, Paris, France

${ }^{7}$ Department of Neuro-anesthesiology, Pitié-Salpêtrière Hospital, Paris, France

${ }^{8}$ Department of Anatomy, University of Paris, Paris, France

${ }^{9}$ Biosurgical Research Lab (Carpentier Foundation), European Georges-Pompidou Hospital, INSERM UMR_S 1140, University of Paris, Paris, France

* Corresponding author and corresponding author for social networks:

Pr Frédéric Clarençon, MD, PhD

Department of Neuroradiology,

Pitié-Salpêtrière Hospital,

Paris, France

Email: frederic.clarencon@aphp.fr

Tel: +33184827300

Cover Title: Flow Diverter Stents: Prediction of Success

Keywords: Flow-diverter stent, Intracranial aneurysm, Machine learning, Occlusion status, Predictive score

Word Count: 3118

Structured abstract: 248

Tables: 3, Illustrations: 1 
57 Background: Complete occlusion of an intracranial aneurysm (IA) after the deployment of a 58 flow-diverter stent (FDS) is currently unpredictable. The aim of the study was to develop a 59 predictive occlusion score based on pre-treatment clinical and angiographic criteria.

60 Methods: Consecutive patients with $\geq 6$ months follow-up were included from 2008 to 2019

61 and retrospectively analyzed. Each IA was evaluated by using the Raymond-Roy occlusion classification (RROC) and dichotomized as occluded (A) or residual (B/C), and $80 \%$ of patients randomly attributed to the training sample. Feature selection and binary outcome prediction relied on logistic regression, and threshold maximizing class separation selected by a CART tree algorithm. The feature selection was addressed by a genetic algorithm selecting among the 30 pre-treatment available variables. Results: The study included 146 patients with 154 IAs. Feature selection yielded a combination of six variables with a good cross-validated accuracy on the test sample, a combination we labeled DIANES score (IA's diameter, indication, parent artery diameters ratio, neck ratio, sidebranch artery, and sex). A score $>-6$ maximized the ability to predict a RROC=A with sensitivity of $87 \%$ (95\%CI: 79\%, 95\%) and specificity of $82 \%(95 \% \mathrm{CI}: 64 \%, 96 \%)$ on the training sample. Accuracy was $86 \%$ (95\%CI: 79\%, 94\%). In the test sample, sensitivity and specificity were $89 \%$ (95\%CI: $77 \%, 98 \%)$ and 60\% (95\%CI: 33\%, 86\%), respectively. Accuracy was $81 \%$ (95\%CI: 69\%, 91\%). status of IA treated with FDS. 
Flow-diverter stents (FDSs) have been widely accepted for the treatment of complex intracranial aneurysms (IAs) (giant/large, large-necked, and/or dissecting/fusiform IAs) and in case of IA recanalization [1]. The effect of FDS is based on two complementary mechanisms that will eventually lead to IA thrombosis: diversion of the blood flow from the IA sac toward the parent artery and endothelialization of the IA's neck promoting a neck sealing. The goal of the treatment is the same as in coils embolization, i.e. a complete obliteration of the IA's sac, assessed by the widely use three-point scale Raymond-Roy occlusion classification (RROC) $[2]$.

However, whether complete IA occlusion will occur after FDS deployment is currently unpredictable. Indeed, the process of IA's sac thrombosis is progressive, with time course ranging from several minutes to several months. In a significant number of cases, there is no occlusion (as high as $24 \%$ at 6 months and $15 \%$ after one year) [1-3]. This delay generates uncertainties for the patient and the operator, absence of early optimal protection against (re)rupture and loss of intra-aneurysmal access because of the FDS's tight mesh. Pre-treatment predisposing factors of complete IA occlusion would be very helpful in many clinical situations to predict the most likely upcoming flow-diverting effect.

Several studies have already shown the existence of factors predictive of aneurysmal occlusion after FDS placement. However, these studies have very varied methodologies: silicon

103 flow models [4], animal models [4,5], computational fluid dynamics (CFD) models [6,7], 104 digital subtraction angiography (DSA)-based optical flow approach [8], or patient cohort 105 studies $[9,10]$. To the best of our knowledge there is no pre-treatment predictive score available 106 in the literature for complete occlusion of IAs treated by FDS. The purpose of our study was to propose a predictive score of complete occlusion of 108 IAs treated with FDS based on initial (i.e.: pre-treatment) clinical and angiographic criteria (DIANES [diameter, indication, artery, neck, exit, sex] score) using machine learning. 


\section{Methods}

\section{Patients}

113 The data that support the findings of this study are available from the corresponding 114 author upon reasonable request. We retrospectively reviewed in a prospectively maintained 115 database the data of patients consecutively treated in our Institution from October 2008 to 116 December 2019 by means of FDSs for IAs. Approval of the institutional review board was 117 obtained; without patient informed consent required. Exclusion criteria were: not assessable IA 118 (carotid-cavernous sinus fistula, parent artery occlusion), unavailable DSA images, and follow119 up $<6$ months (loss to follow-up, death).

120 We systematically reviewed: patients' demographics: age, sex; IAs' characteristics: 121 type, location, configuration (saccular unilobular or complex [10] [fusiform, dysmorphic, 122 multilobular]), sizing, neck ratio (NR) [11] (ratio of diameters of the neck and the parent artery), 123 ruptured or unruptured IA, indication (first treatment, recanalization), presence of a side-branch 124 artery incorporated into the IA, and contrast agent stagnation at venous phase; parent artery' 125 characteristics: diameters ( $5 \mathrm{~mm}$ upstream to the neck and $5 \mathrm{~mm}$ downstream), diameters ratio 126 (PDR), curvature of the parent artery in relation to the tangent passing through the neck of the 127 IA (acute angle: concavity, no angle: straightness, obtuse angle: convexity), and inflow angle 128 [12]; as well as devices' characteristics: type, number, and associate coiling.

\section{Management}

131 Prior to the procedure, the neuroradiology team collegially assessed the characteristics 132 of each aneurysm and treatment modalities were discussed at a multidisciplinary meeting 133 (including neurosurgeons and neurointensivists).

134 All patients received dual-antiplatelet therapy (clopidogrel and aspirin) 5 days before 135 stenting. In case of clopidogrel resistance (assessed by a platelet-aggregation test: Multi-plate 136 [Roche Diagnostics]), patients were treated with ticagrelor for 6 months after the procedure. If 
the platelet-aggregation test was satisfactory, patients were maintained on dual antiplatelet

138 therapy for at least 6 months after the procedure, followed by aspirin alone during 6 months.

139 Procedures were performed under general anesthesia through femoral access. The

140 FDSs were deployed using a tri-axial guiding-catheter system (using a 6 French long sheath, a

1415 or $6 \mathrm{~F}$ supple intermediate support catheter and a 0.027 " microcatheter). Five commercially

142 available devices were used: the Pipeline Embolization Device (PED, PED Flex [Covidien]),

143 the Silk (Balt), the Flow-Redirection Endoluminal Device (FRED [MicroVention]), the Surpass

144 (Streamline, Evolve [Stryker]) and the p64 (Phenox).

\section{Outcome}

MRI was performed at 6-month, DSA at 1-year, and MRI/DSA at last follow-up. The last follow-up is defined as the date with the last available imaging control of the aneurysmal occlusion (by MRI or DSA). Based on their last follow-up, IAs were dichotomized as occluded $(\mathrm{RROC}=\mathrm{A})$ or residual $(\mathrm{RROC}=\mathrm{B} / \mathrm{C})[2]$. A junior (in-training) and two senior interventional

151 neuroradiologists (with five and twelve years of experience) independently reviewed the 152 follow-up imaging studies, blinded to the clinical data. Discrepancies were settled by consensus 153 agreements. The primary outcome was the last available scoring for patients followed at least 1546 months, with only RROC=A scored patients being considered successes.

\section{Statistical analysis}

$80 \%$ of the aneurysm cases were randomly attributed to the learning set while the

158 remaining $20 \%$ were kept as an untouched test set. Subsequently, a separate set of 27 newly

159 gathered aneurysms was fused to the randomly selected test set. Quantitative variables were 160 discretized by manually selecting limits maximizing success/failure separation on the training 161 set close to the ones a rpart tree algorithm would have chosen using the "outcome" as variable 162 to be classified, yielding at least 20 cases per interval (subgroups being the result of splitting a 163 variable on the train set, and not each of the intersections of said split variable with the 164 "outcome" variable) and if possible, thresholds being rounded enough to make for a clinically 
acceptable score. The impurity allowing class separation by an rpart tree was based on the information index [13]. Feature selection and binary outcome prediction relied on elasticnet

167 [14] penalized logistic regression (LR). Class weighting accounted for the unequal number of cases in the success and failure groups.

To enhance the interpretability and performance of the model, a subset of available features may prove more efficient than the full feature range. We chose a genetic algorithm as a means to explore the possible predictor variable combinations more efficiently than stepwiseforward and -backward algorithms commonly used in medicine [15-17]. We ran the variable selection genetic algorithm with a $0 / 1$ numerical encoding (allowing for example a single

174 coefficient for gender=male to represent the gender variable, instead of having 2 opposite 175 coefficients). This well-described algorithm initially draws a number of predictor combinations, 176 and tests the predictive ability of logistic regressions using said combinations of predictors by 177 10-fold cross validation within the "train" cohort. Only the most efficient combinations are 178 allowed to proceed to the following generation, where a mixture of "mutation" (random 179 addition or deletion of a predictor within a combination) and "crossover" (the random matching 180 of the $\mathrm{x}$-first variables a priory successful combination to the y-last of another combination) 181 creates new combinations to be tested.

182 The algorithm was allowed to proceed for 200 generations of 40 'genotypes' each (mutation 183 rate: 0.15 , maximum features per genotype: 20$)$. The penalization parameter 's' for predictions 184 was set to 0.02 , and among the tested performance criteria (mean misclassification error, sum 185 or product of true positive rate and accuracy), prediction area under the curve proved the most 186 efficient (averaged prediction on the validation sample of each cross-validation performed on 187 the training dataset). To obtain an efficient elasticnet mixing parameter, a grid tuning was subsequently

189 performed for each of the most promising feature sets from the precedent step with a second 190 cross validated penalized and weighted LR, always on the training subset of data. Each of the 191 selected feature sets with its proposed elasticnet mixing parameter was then used in a LR trained on the full training dataset and evaluated by its max (accuracy + true positive rate) 
193 over the range of thresholds (where FDS failure is considered as the positive class). The

194 model was transformed into score by extracting beta coefficients, and the threshold chosen to

195 maximize "accuracy + balanced accuracy" on the training set.

196 The interobserver reliability was assessed by calculation of Kappa ( $\kappa)$ values, 197 categorized as: 0.41-0.6, 0.61-0.8, and 0.81-1 indicating moderate, good, and excellent 198 agreement, respectively.

199 All statistical analyses were performed using R (3.4.1) and RStudio (1.0.153); packages

200 were: car, caret, Hmisc, rpart, ggplot2, questionr, corrplot, dummies, pROC and reshape.

201 Regression was done using glmnet embedded in the $m l r$ package.

202

203 
One hundred and seventy-nine patients were screened for eligibility during the study period. Thirty-three patients were excluded for lost to follow-up $(n=25)$, parent artery occlusion $(n=3)$, death $(n=4)$, and FDS for carotid-cavernous fistula treatment $(n=1)$. The four early $(<6$ months) deaths were due to: an early hematoma with death at the eighth day after the treatment with FDS and coils of a giant aneurysm of the middle cerebral artery, a complication of dual

211 anti-platelet therapy with death twenty-three days after stenting, a retroperitoneal hematoma 212 requiring the interruption of dual anti-platelet therapy leading to cerebral ischemic and 213 hemorrhagic complication with death on the seventh day, and a fatal hemorrhagic 214 transformation after cerebral infarction. The parent artery occlusions by coils were due to one intra-aneurysmal stent migration in a giant intracavernous aneurysm and two misopening of the FDS. One hundred forty-six patients (one hundred fifty-four IAs) were included in this study.

217 They were randomly assigned to the learning cohort (80\%) or the validation cohort (20\%).

218 Patients, IAs and parent arteries pre-stenting characteristics are summarized in Table 1. The 219 overall median follow-up was 14.4 months (interquartile range [IQR]: 11.9-30.4). The 220 distribution of the devices was as follows: nitinol: $\mathrm{n}=18$ Silk $(11 \%), \mathrm{n}=2$ FRED $(1.2 \%), \mathrm{n}=$ 2214 p64 (2.4\%) and cobalt-chromium alloy: $\mathrm{n}=128$ PED $(78 \%), \mathrm{n}=12$ Surpass $(7.3 \%)$. A second 222 telescopic FDS was required in ten cases (6.5\%). No procedure required more than two FDS. 223 In 23 cases (14.9\%), the coiling of the aneurysmal sac was performed before stenting because 224 of the large diameter of the IA (median diameter: $10 \mathrm{~mm}$, IQR: 6.9-13.9). 117 IAs were 225 assigned to group $\mathrm{RROC}=\mathrm{A}$ (complete obliteration), 37 IAs were assigned to group $226 \mathrm{RROC}=\mathrm{B} / \mathrm{C}(\mathrm{n}=15$ for residual neck and $\mathrm{n}=22$ for residual IA, respectively). Interreader 227 agreement for RROC status evaluated at last follow-up by MRI or DSA was considered as 228 excellent with $\kappa=0.88\left({ }_{95 \%} \mathrm{CI}: 0.79-0.98\right)$ and good for the assessment of side-branch artery 229 and parent artery curvature: $\kappa=0.78(95 \% \mathrm{CI}: 0.62-0.96)$ and $\kappa=0.71\left({ }_{95 \%} \mathrm{CI}: 0.53-0.90\right)$, 230 respectively. The median of the last follow-up was 14.9 months (IQR: 12.1-29.8) and the mean 231 was 23.3 months (standard deviation $[\mathrm{SD}]=18.2$ months) in the RROC=A group, and the 
232 median of the last follow-up was 13.4 months (IQR: 10.1-30.8) and the mean was 22.0 months

$233(\mathrm{SD}=19.5$ months $)$ in the $\mathrm{RROC}=\mathrm{B} / \mathrm{C}$ group.

234

235 Table 1: Patients, Intracranial Aneurysms and Parent Arteries Initial Characteristics

\begin{tabular}{|c|c|c|}
\hline Parameters & Train & Test \\
\hline Patients & 98 & 51 \\
\hline Female & $77(79)$ & $44(86)$ \\
\hline Age (years)* & $50(39-56)$ & $54(45-59)$ \\
\hline Intracranial aneurysms (IAs) & 102 & 52 \\
\hline Diameter $(\mathrm{mm}) *$ & $7(5-9.88)$ & $6.31(4.25-12.48)$ \\
\hline Neck $(\mathrm{mm})^{*}$ & $4.6(3.5-6.15)$ & $4.82(3.92-6.73)$ \\
\hline Dome-to-neck ratio (DNR)* & $1.4(1.08-1.79)$ & $1.39(1.14-2)$ \\
\hline $\begin{array}{l}\text { Locations: } \\
\text { Anterior circulation: Carotid-ophthalmic }\end{array}$ & 40 & 24 \\
\hline Posterior communicating artery & 12 & 4 \\
\hline Supraclinoid ICA & 4 & 0 \\
\hline Cavernous ICA & 10 & 3 \\
\hline ICA Siphon & 5 & 11 \\
\hline $\begin{array}{l}\text { Anterior communicating and } \\
\text { anterior cerebral arteries }\end{array}$ & 5 & 3 \\
\hline Middle cerebral artery & 5 & 1 \\
\hline Anterior choroidal artery & 1 & 3 \\
\hline Superior hypophyseal artery & 1 & 2 \\
\hline Posterior circulation: Vertebral artery & 8 & 0 \\
\hline Posterior cerebral artery & 4 & 0 \\
\hline Basilar artery & 4 & 0 \\
\hline $\begin{array}{l}\text { Superior and posterior inferior } \\
\text { cerebellar arteries }\end{array}$ & 3 & 1 \\
\hline $\begin{array}{l}\text { Type: } \\
\text { Saccular }\end{array}$ & $82(80.4)$ & $45(86.5)$ \\
\hline Dissecting aneurysm & $4(3.9)$ & $1(1.9)$ \\
\hline Large/giant partially thrombosed & $8(7.8)$ & $1(1.9)$ \\
\hline Fusiform & $4(3.9)$ & 0 \\
\hline Blister-like & $4(3.9)$ & $5(9.6)$ \\
\hline Indication: Recanalization & $34(33)$ & $14(27)$ \\
\hline Ruptured IA & $27(26)$ & $12(23)$ \\
\hline Contrast media stagnation & $27(26)$ & $18(35)$ \\
\hline Incorporated side-branch artery: Yes & $18(18)$ & $12(23)$ \\
\hline Diameter $(\mathrm{mm})^{*}$ & $1.1(0.8-1.5)$ & $1.15(0.97-1.53)$ \\
\hline Configuration: Complex & $82(80)$ & $45(87)$ \\
\hline \multicolumn{3}{|l|}{ Parent arteries } \\
\hline Diameters: Upstream $(\mathrm{mm})^{*}$ & $3.7(3.1-4.1)$ & $4.1(3.57-4.5)$ \\
\hline Downstream $(\mathrm{mm})^{*}$ & $3.1(2.62-3.4)$ & $3.2(2.87-3.6)$ \\
\hline Average $(\mathrm{mm}) *$ & $3.35(2.91-3.74)$ & $3.65(3.28-4.03)$ \\
\hline Upstream/downstream ratio (PDR) * & $1.19(1.06-1.37)$ & $1.26(1.14-1.36)$ \\
\hline Neck / parent artery diameters ratio (NR)* & $1.44(1.03-1.95)$ & $1.34(1.07-1.87)$ \\
\hline
\end{tabular}




\begin{tabular}{|c|l|l|}
\hline${\text { Geometry: Inflow angle }\left(\text { degree }^{\circ}\right)^{*}}$ & $135(95-163)$ & $135(103-168)$ \\
\hline Convex Curvature $^{*}$ & $50(49)$ & $20(38)$ \\
\hline
\end{tabular}

237 Note: unless otherwise indicated, data are number of patients, with percentage in brackets.

$238 *$ Data are median with the interquartile range (IQR) in brackets.

$239 \mathrm{ICA}=$ internal carotid artery, $\mathrm{n}=$ number, $\mathrm{NR}=$ neck ratio, $\mathrm{PDR}=$ parent artery diameters ratio.

241 Training Sample

242 Six variables were included in the DIANES score. The score ranged from -24 to 4

243 points (Table 2). The median score was -3 (IQR: -7-2) in the overall cohort. Among failed 244 occlusion $(\mathrm{RROC}=\mathrm{B} / \mathrm{C})$ the median score was $-8(\mathrm{IQR}:-10-5)$ and -2 (IQR: $-4-2)$ among 245 successful occlusion $(\mathrm{RROC}=\mathrm{A})$. In receiver operating characteristic analysis, a score greater 246 than -6 maximized the ability to predict a complete occlusion ( $\mathrm{RROC}=\mathrm{A})$. The score accuracy 247 was 0.86 (95\% CI: $0.79-0.94)$, with sensitivity of 0.87 (95\% CI: $0.79-0.95)$ and specificity of 0.82 248 (95\%CI: 0.64-0.96) (Table 3, Fig 1).

Test Sample and Whole Cohort

In the test sample, a DIANES score greater than -6 was predictive of complete 252 occlusion (RROC=A), with sensitivity of 0.89 (95\% CI: $0.77-0.98)$ and specificity of $0.60\left({ }_{95 \%} \mathrm{CI}\right.$ : 253 0.33-0.86). The score accuracy was 0.81 (95\%CI: 0.69-0.91) (Table 3, Fig 1). In the whole 254 cohort, a DIANES score greater than -6 was predictive of complete occlusion (RROC=A), with 255 sensitivity of 0.88 (95\% CI: $0.82-0.94)$ and specificity of 0.73 (95\% CI: $0.58-0.87)$. The score 256 accuracy was 0.84 (95\%CI: 0.78-0.90) (Table 3, Fig 1). The DIANES score was able to divide 257 the whole cohort from either side of the threshold value (-6 points) in both success (RROC=A) 258 and failure $(\mathrm{RROC}=\mathrm{B} / \mathrm{C})$ groups at last follow-up (Fig 1). Additional representations have been 259 added to the supplemental material with their accuracies ( $\left.{ }_{95 \%} \mathrm{CI}\right)$ on training and test samples: a 260 recursive partitioning CART tree, a penalized logistic regression LASSO, and a simplified 261 version of the DIANES score. 
Table 2: DIANES Score Components and Scoring Parameters

\begin{tabular}{|c|c|}
\hline Component & \multirow[t]{2}{*}{ Score } \\
\hline 1. Sex & \\
\hline Male & 4 \\
\hline 2. Indication & \\
\hline Recanalization & -5 \\
\hline 3. Side-branch artery & \\
\hline Yes & -8 \\
\hline 4. Aneurysm's diameter $(\mathbf{m m})$ & \\
\hline$>8.9$ & -5 \\
\hline 5. Neck ratio (NR) & \\
\hline$>1.1 ; 1.8 \leq$ & -2 \\
\hline 6. Parent artery diameters ratio (PDR) & \\
\hline$>1.3$ & -4 \\
\hline Threshold (under $=$ predictive of failure) & -6 \\
\hline
\end{tabular}

265 Note: the score is the sum of the points of the seven criteria. The threshold maximizing class

266 separation (i.e.: $\mathrm{RROC}=\mathrm{A}$ and $\mathrm{RROC}=\mathrm{B} / \mathrm{C}$ ), a score below two was predictive of incomplete occlusion $(\mathrm{RROC}=\mathrm{B} / \mathrm{C})$.

DIANES score $=$ diameter, indication, artery, neck, exit, sex score, RROC $=$ Raymond-Roy occlusion classification.

Table 3: Sensitivities, Specificities and Predictive Values for the DIANES Score

\begin{tabular}{|c|c|c|c|c|c|c|}
\hline & Accuracy & Sensitivity & Specificity & $\begin{array}{c}\text { Positive } \\
\text { Predictive } \\
\text { Value } \\
\text { (PPV) } \\
\end{array}$ & $\begin{array}{c}\text { Negative } \\
\text { Predictive } \\
\text { Value } \\
\text { (NPV) } \\
\end{array}$ & AUC \\
\hline $\begin{array}{l}\text { Training } \\
\text { sample }\end{array}$ & $\begin{array}{c}0.86(0.79 \\
0.94)\end{array}$ & $\begin{array}{c}0.87(0.79, \\
0.95) \\
{[70 / 80]}\end{array}$ & $\begin{array}{c}0.82(0.64, \\
0.96) \\
{[18 / 22]}\end{array}$ & $\begin{array}{c}0.95(0.88, \\
0.99) \\
{[70 / 74]}\end{array}$ & $\begin{array}{c}0.64(0.45, \\
0.83) \\
{[18 / 28]}\end{array}$ & $\begin{array}{c}0.88(0.80 \\
0.96)\end{array}$ \\
\hline $\begin{array}{c}\text { Test } \\
\text { sample }\end{array}$ & $\begin{array}{c}0.81(0.69 \\
0.91)\end{array}$ & $\begin{array}{c}0.89(0.77 \\
0.98) \\
{[33 / 37]}\end{array}$ & $\begin{array}{c}0.60(0.33, \\
0.86) \\
{[9 / 15]}\end{array}$ & $\begin{array}{c}0.86(0.72, \\
0.95) \\
{[33 / 37]}\end{array}$ & $\begin{array}{c}0.66(0.41, \\
0.93) \\
{[9 / 13]}\end{array}$ & $\begin{array}{c}0.73(0.55 \\
0.91)\end{array}$ \\
\hline $\begin{array}{l}\text { Whole } \\
\text { cohort }\end{array}$ & $\begin{array}{c}0.84(0.78 \\
0.90)\end{array}$ & $\begin{array}{c}0.88(0.82, \\
0.94) \\
{[103 /} \\
117] \\
\end{array}$ & $\begin{array}{c}0.73(0.58 \\
0.87) \\
{[27 / 37]}\end{array}$ & $\begin{array}{c}0.91(0.85 \\
0.96) \\
{[103 /} \\
113] \\
\end{array}$ & $\begin{array}{c}0.66(0.51 \\
0.81) \\
{[27 / 41]}\end{array}$ & $\begin{array}{c}0.83(0.74 \\
0.91)\end{array}$ \\
\hline
\end{tabular}

275 Note: Data are percentages; data in parentheses are 95\% confidence intervals (CIs); data in

276 brackets are numerator/denominator.

277 DIANES score = diameter, indication, artery, neck, exit, sex score. 


\section{Discussion}

The evolution of the clinical practice and the current knowledge in the field of FDS

280 requires a better prediction of IA occlusion after stenting by FDS. Currently, the prediction of

281 IA's thrombosis can either be based on descriptive grading scales using DSA images $[18,19]$, 282 parametric color coding [20] or CFD models [21]. Furthermore, off-label applications of the 283 FDSs have been reported [22] such as ruptured IAs [23], requiring an even more accurate 284 prediction. Moreover, FDSs are associated with an elevated rate (34\%) of ipsilateral de novo 285 fluid-attenuated inversion recovery (FLAIR) lesions, most likely due to delayed 286 thromboembolic events from the FDS/IA complex before complete healing of the IA [24]. In our cohort, the DIANES score is associated with long-term aneurysmal sac occlusion in patients treated with FDS. The score is based on six items: two clinical criteria (i/sex, 289 ii/indication) and four imaging criteria regarding the morphology of the IA (iii/side-branch artery, iv/diameter, v/NR) and the parent artery (vi/PDR). These criteria have already been 291 described as predictive in the literature.

292 Regarding the clinical criteria of the score: i/The DIANES score reflects vascular gender 293 differences, with males predicting a higher occlusion rate. Indeed, sex steroid hormones are 294 well-known factors involved in IAs' pathogenesis [25] but their role in vascular remodeling 295 after stenting is poorly known. Moreover, circulating bone marrow-derived endothelial progenitor cells (PCs) play an important role in vascular repair [26] and endothelialization of 297 the FDS's mesh [26]. However, women have lower PCs levels compared to men and are likely 298 to reach a critically low level with aging [27] ; ii/In our score, an FDS indication for a 299 recanalized IA is a less favorable situation. Healing of a coiled IA is a dynamic process 300 occurring within the first four weeks after embolization and recanalization occurs in $10-20 \%$ of 301 cases [28]. Indeed, although FDSs are a well-recognized treatment of recurrent IAs, it could be 302 hypothesized that several mechanisms underlying the recanalization pathophysiology [28] such 303 as active vascular wall disease, poor quality neointima formation across the neck, or significant 304 transmission of blood pulsation affecting the thrombus stability [5] may also affect the efficacy 305 of the stent. 
Regarding the morphological criteria of the score: iii/The existence of a side-branch artery

307 arising from the sac has been previously demonstrated as a negative predicting factor for IA's 308 occlusion [9,29] diminishing the 'flow-diverting effect'; iv/FDS seems to be a relatively safe 309 and effective technique for large and giant unruptured IAs embolization [30] but the success of 310 occlusion could depend on the neck size [4]. In these cases, occlusion failures could be 311 explained by holes in the neointima lining the FDS [31] ; v/In the literature, NR was described as a predictive factor of occlusion [11], whereas larger neck diameters [4,5] and lower dome-

313 to-neck ratios [29] were negative predictive criteria. The NR is a predictor of failure and 314 suggests that a larger defect in the parent artery provides the input for blood flow into RROC 315 B/C IAs. This would result in higher flow in the IA sac, which represents a greater burden for 316 flow diversion and thus less effective treatment of FDS [11]. Ostium enlargement has been 317 correlated with the rate of IA occlusion after flow diversion in animal model studies $[4,32]$; 318 vi/At last, in our score, a higher PDR could also reflect an increased risk of FDS oversizing and 319 poor wall apposition. Oversizing could be associated with lower pore density and metal 320 coverage resulting in increased porosity of the FDS [33] and malapposition [29] results in the 321 risk of endoleak and failure of endothelialization.

322 During the follow-up period of IAs treated with FDSs, there was no further treatment 323 of the IAs. The reasons for the lack of a second treatment was that the majority of IAs were 324 unruptured, occlusion of the IA could occur in the medium to long term, and in most cases the 325 only additional treatment available would be another FDS which would increase the risks 326 associated with this device.

The statistical model chosen was a genetic algorithm for the selection of variables.

328 Genetic algorithms do not guarantee to obtain the global maximum accuracy but represent a 329 trade-off between greedy algorithms like stepwise ascent or descent, and extreme time330 consuming exploration of all available predictor variable combinations. Mimicking aspects of 331 Darwinian processes for machine learning was already hypothesized as a fruitful branch to 332 explore by Alan Turing in 1950, and progressively came to use in the 1970s and 1980s. Genetic 333 algorithms usually outperform stepwise ascent or descent in variable selection for model 
334 creation [15,16]. Recently, machine learning analysis has been used in the field of 335 interventional neuroradiology [34,35].

336 We acknowledge potential limitations of our study, including the need for an external 337 validation of the score with patients from different centers and larger cohorts. We recognize the 338 relative complexity of the score given the variance of the weighting, but it includes only six 339 variables that can be easily and routinely assessed from the clinic and imaging data. In addition, 340 the possibility of very late appearance of complete thrombosis in an initially RROC=B/C IA 341 cannot be ruled out. Also, we have chosen to include ten patients treated with two FDSs as this 342 variable was not retained during the statistical selection step and furthermore, this factor is not 343 usually used in predictive studies. Finally, the IA thrombosis is a complex spatio-temporal 344 process mediated by several mechanisms such as vascular morphology, biochemical factors 345 produced by the IA wall, blood flow patterns and biomechanical factors of the FDS including 346 endothelialization of the device's struts, and should thus not be limited to clinico-angiographic 347 data. Our score was developed for its ability to predict the occlusion of an IA treated with FDS; 348 it does not take into account other important outcomes in the choice of treatment such as the 349 occurrence of a complication (e.g. ischemic stroke).

350 This opens the field of a more personalized patient management because of an IA-specific 351 complete thrombosis threshold [21]. Despite these limitations, improved standardization of pre352 treatment assessment with the use of the DIANES score is intended to provide a radioclinical 353 tool to predict success after FDS implantation in routine clinical care. This score may provide 354 a predictive stratification of FDS success for assessment of new treatments in therapeutic trials. 
364 imaging morphological features of both the IA and the parent artery, showed an association 365 with the final occlusion status. This clinico-radiological grading scale, built on components 366 easily assessed routinely, needs to be tested in a larger separate validation cohort and could be 367 used for the selection of therapeutic alternatives for exclusion treatment in patients with IAs. 368 


\section{Disclosures}

393 Pr Frédéric Clarençon reports conflict of interest with Medtronic, Guerbet, Balt Extrusion

394 (payment for readings), Codman Neurovascular (core lab). Dr Nader Sourour is consultant for 395 Medtronic, Balt Extrusion, Microvention, Stock/Stock Options: Medina. The other authors 396 report no conflict of interest concerning the materials or methods used in this study or the 397 findings specified in this paper. The manuscript is not supported by industry.

\section{Competing Interests}

400 None.

\section{Contributorship Statement}

403 Conception and design: AG, CT, FC; Acquisition of data: AG, ES, NS, FC; Analysis and 404 interpretation of data: AG, CT, FC; Drafting the article: AG, CT, FC; Critically revising the 405 article: ES, JG, BM, KP, SL, VD; Reviewed submitted version of manuscript: AG, CT, FC; 406 Approved the final version of the manuscript on behalf of all authors: FC.

\section{$407 \quad$ Funding}

408 None.

\section{Data Availability}

411 The data that support the findings of this study are available from the corresponding author 412 upon reasonable request.

\section{Research Ethics Approval}

415 Approval of the institutional review board was obtained (CPP-Ile-de-France VI, Groupe 416 Hospitalier Pitié-Salpêtrière, Pr Nathalie BRION, June 14 ${ }^{\text {th }}$ 2019); without patient informed 417 consent required. 


\section{References}

1 Brinjikji W, Murad MH, Lanzino G, et al. Endovascular Treatment of Intracranial Aneurysms With Flow Diverters: A Meta-Analysis. Stroke 2013;44:442-7. doi:10.1161/STROKEAHA.112.678151

2 Roy D, Milot G, Raymond J. Endovascular treatment of unruptured aneurysms. Stroke 2001;32:1998-2004. doi:10.1161/hs0901.095600

3 Becske T, Kallmes DF, Saatci I, et al. Pipeline for Uncoilable or Failed Aneurysms: Results from a Multicenter Clinical Trial. Radiology 2013;267:858-68. doi:10.1148/radiol.13120099

4 Gentric JC, Darsaut TE, Makoyeva A, et al. The Success of Flow Diversion in Large and Giant Sidewall Aneurysms May Depend on the Size of the Defect in the Parent Artery. Am J Neuroradiol 2014;35:2119-24. doi:10.3174/ajnr.A4010

5 Cebral JR, Mut F, Raschi M, et al. Analysis of Hemodynamics and Aneurysm Occlusion after Flow-Diverting Treatment in Rabbit Models. Am J Neuroradiol 2014;35:1567-73. doi:10.3174/ajnr.A3913

6 Xiang J, Damiano RJ, Lin N, et al. High-fidelity virtual stenting: modeling of flow diverter deployment for hemodynamic characterization of complex intracranial aneurysms. J Neurosurg 2015;123:832-40. doi:10.3171/2014.11.JNS14497

7 Mut F, Raschi M, Scrivano E, et al. Association between hemodynamic conditions and occlusion times after flow diversion in cerebral aneurysms. J NeuroInterventional Surg 2015;7:286-90. doi:10.1136/neurintsurg-2013-011080

8 Pereira VM, Bonnefous O, Ouared R, et al. A DSA-Based Method Using ContrastMotion Estimation for the Assessment of the Intra-Aneurysmal Flow Changes Induced by Flow-Diverter Stents. Am J Neuroradiol 2013;34:808-15. doi:10.3174/ajnr.A3322

9 Brasiliense LBC, Aguilar-Salinas P, Miller DA, et al. Analysis of Predictors and Probability of Aneurysm Occlusion in the Internal Carotid Artery After Treatment with Pipeline Embolization Device. World Neurosurg 2017;107:641-8. doi:10.1016/j.wneu.2017.08.099

10 Dodier P, Frischer JM, Wang W-T, et al. Immediate Flow Disruption as a Prognostic Factor After Flow Diverter Treatment: Long-Term Experience with the Pipeline Embolization Device. World Neurosurg 2018;113:e568-78. doi:10.1016/j.wneu.2018.02.096

11 Paliwal N, Tutino VM, Shallwani H, et al. Ostium Ratio and Neck Ratio Could Predict the Outcome of Sidewall Intracranial Aneurysms Treated with Flow Diverters. Am J Neuroradiol 2019;40:288-94. doi:10.3174/ajnr.A5953

12 Beller E, Klopp D, Göttler J, et al. Closed-Cell Stent-Assisted Coiling of Intracranial Aneurysms: Evaluation of Changes in Vascular Geometry Using Digital Subtraction Angiography. PLOS ONE 2016;11:e0153403. doi:10.1371/journal.pone.0153403

13 Therneau TM, Atkinson EJ. An Introduction to Recursive Partitioning Using the RPART Routines. Mayo Foundation. Cranr-Proj. 2019.https://cran.rproject.org/web/packages/rpart/vignettes/longintro.pdf (accessed 26 Oct 2020). 
14 Zou H, Hastie T. Regularization and Variable Selection via the Elastic Net. J R Stat Soc Ser B Stat Methodol 2005;67:301-20.

15 Vinterbo S, Ohno-Machado L. A genetic algorithm to select variables in logistic regression: example in the domain of myocardial infarction. Proc AMIA Symp $1999 ;: 984-8$.

16 Johnson P, Vandewater L, Wilson W, et al. Genetic algorithm with logistic regression for prediction of progression to Alzheimer's disease. BMC Bioinformatics 2014;15:S11. doi:10.1186/1471-2105-15-S16-S11

17 Sale M, Sherer EA. A genetic algorithm based global search strategy for population pharmacokinetic/pharmacodynamic model selection: Genetic algorithm in PK/PD model selection. Br J Clin Pharmacol 2015;79:28-39. doi:10.1111/bcp.12179

18 Kamran M, Yarnold J, Grunwald IQ, et al. Assessment of angiographic outcomes after flow diversion treatment of intracranial aneurysms: a new grading schema. Neuroradiology 2011;53:501-8. doi:10.1007/s00234-010-0767-5

19 Grunwald IQ, Kamran M, Corkill RA, et al. Simple Measurement of Aneurysm Residual after Treatment: the SMART scale for evaluation of intracranial aneurysms treated with flow diverters. Acta Neurochir (Wien) 2012;154:21-6. doi:10.1007/s00701-011-1177-0

20 Gölitz P, Struffert T, Rösch J, et al. Cerebral aneurysm treatment using flow-diverting stents: in-vivo visualization of flow alterations by parametric colour coding to predict aneurysmal occlusion: preliminary results. Eur Radiol 2015;25:428-35. doi:10.1007/s00330-014-3411-7

21 Kulcsár Z, Augsburger L, Reymond P, et al. Flow diversion treatment: intra-aneurismal blood flow velocity and WSS reduction are parameters to predict aneurysm thrombosis. Acta Neurochir (Wien) 2012;154:1827-34. doi:10.1007/s00701-012-1482-2

22 Murthy SB, Shah J, Mangat HS, et al. Treatment of Intracranial Aneurysms With Pipeline Embolization Device: Newer Applications and Technical Advances. Curr Treat Options Neurol 2016;18:16. doi:10.1007/s11940-016-0399-0

23 Lin N, Brouillard AM, Keigher KM, et al. Utilization of Pipeline embolization device for treatment of ruptured intracranial aneurysms: US multicenter experience. $J$ NeuroInterventional Surg 2015;7:808-15. doi:10.1136/neurintsurg-2014-011320

24 Safain MG, Roguski M, Heller RS, et al. Flow Diverter Therapy With the Pipeline Embolization Device Is Associated With an Elevated Rate of Delayed Fluid-Attenuated Inversion Recovery Lesions. Stroke 2016;47:789-97. doi:10.1161/STROKEAHA.115.010522

25 Boese AC, Kim SC, Yin K-J, et al. Sex differences in vascular physiology and pathophysiology: estrogen and androgen signaling in health and disease. Am J PhysiolHeart Circ Physiol 2017;313:H524-45. doi:10.1152/ajpheart.00217.2016

26 Iwakura A, Luedemann C, Shastry S, et al. Estrogen-Mediated, Endothelial Nitric Oxide Synthase-Dependent Mobilization of Bone Marrow-Derived Endothelial Progenitor Cells Contributes to Reendothelialization After Arterial Injury. Circulation 2003;108:3115-21. doi:10.1161/01.CIR.0000106906.56972.83 
27 Topel ML, Hayek SS, Ko Y, et al. Sex Differences in Circulating Progenitor Cells. J Am Heart Assoc 2017;6. doi:10.1161/JAHA.117.006245

28 Brinjikji W, Kallmes DF, Kadirvel R. Mechanisms of Healing in Coiled Intracranial Aneurysms: A Review of the Literature. Am J Neuroradiol 2015;36:1216-22. doi:10.3174/ajnr.A4175

29 Shapiro M, Becske T, Nelson PK. Learning from failure: persistence of aneurysms following pipeline embolization. J Neurosurg 2017;126:578-85. doi:10.3171/2015.12.JNS152065

30 Cagnazzo F, Mantilla D, Rouchaud A, et al. Endovascular Treatment of Very Large and Giant Intracranial Aneurysms: Comparison between Reconstructive and Deconstructive Techniques-A Meta-Analysis. Am J Neuroradiol 2018;39:852-8. doi:10.3174/ajnr.A5591

31 Darsaut TE, Bing F, Makoyeva A, et al. Flow Diversion of Giant Curved Sidewall and Bifurcation Experimental Aneurysms with Very-Low-Porosity Devices. World Neurosurg 2014;82:1120-6. doi:10.1016/j.wneu.2013.09.036

32 Chung B, Mut F, Kadirvel R, et al. Hemodynamic analysis of fast and slow aneurysm occlusions by flow diversion in rabbits. J Neurointerventional Surg 2015;7:931-5. doi:10.1136/neurintsurg-2014-011412

33 Makoyeva A, Bing F, Darsaut TE, et al. The Varying Porosity of Braided Self-Expanding Stents and Flow Diverters: An Experimental Study. Am J Neuroradiol 2013;34:596-602. doi:10.3174/ajnr.A3234

34 Podgorsak AR, Rava RA, Shiraz Bhurwani MM, et al. Automatic radiomic feature extraction using deep learning for angiographic parametric imaging of intracranial aneurysms. J NeuroInterventional Surg 2020;12:417-21. doi:10.1136/neurintsurg-2019015214

35 Ramos LA, van der Steen WE, Sales Barros R, et al. Machine learning improves prediction of delayed cerebral ischemia in patients with subarachnoid hemorrhage. $J$ NeuroInterventional Surg 2019;11:497-502. doi:10.1136/neurintsurg-2018-014258 


\section{Figure 1 Legends:}

535 Above: Graphs showing receiver operating characteristic (ROC) curves with area under the 536 curve (AUC) and 95\% confidence intervals (CIs) for occlusion prediction in the training sample 537 (A), in the test sample (B), and in the whole cohort (C).

538 Below: Dot plot displaying patients' distribution from either side of the threshold value of the

539 DIANES score (two points) in both success $(\mathrm{RROC}=\mathrm{A})$ and failure $(\mathrm{RROC}=\mathrm{B} / \mathrm{C})$ groups at last 540 follow-up in the whole cohort.

541 DIANES score $=$ diameter, indication, artery, neck, exit, sex score, RROC $=$ Raymond-Roy 542 occlusion classification. 
Supplemental material:

\section{Recursive partitioning CART tree from the quantitative variables:}

\section{Recursive partitionning} with quantitative variables

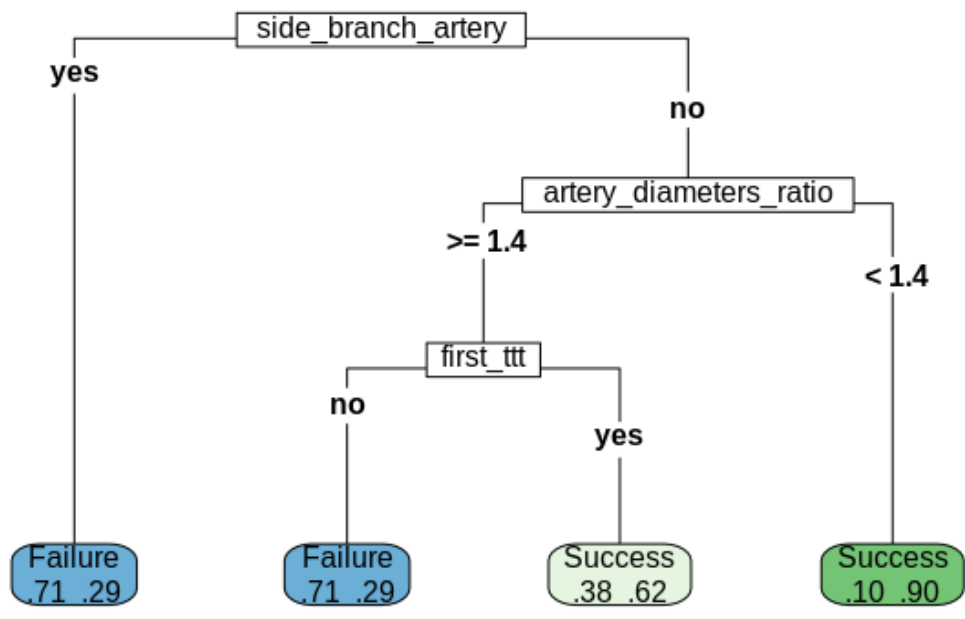

\begin{tabular}{|c|c|l|l|c|c|c|}
\hline CART tree & Accuracy & Sensitivity & Specificity & $\begin{array}{c}\text { Positive } \\
\text { Predictive } \\
\text { Value } \\
\text { (PPV) }\end{array}$ & $\begin{array}{c}\text { Negative } \\
\text { Predictive } \\
\text { Value } \\
\text { (NPV) }\end{array}$ & $\begin{array}{c}\text { Balanced } \\
\text { Accuracy }\end{array}$ \\
\hline $\begin{array}{c}\text { Training } \\
\text { sample }\end{array}$ & $\begin{array}{c}0.8137 \\
95 \% \text { CI }: \\
(0.7245, \\
0.884)\end{array}$ & 0.8500 & 0.6818 & 0.9067 & 0.5556 & 0.7659 \\
\hline Test sample & $\begin{array}{c}0.7692 \\
95 \% \mathrm{CI}: \\
(0.6316, \\
0.8747)\end{array}$ & 0.8649 & 0.5333 & 0.8205 & 0.6154 & 0.6991 \\
\hline
\end{tabular}


Penalized logistic regression LASSO from qualitatively rendered variables:

\begin{tabular}{|l|c|}
\hline Component & Score \\
\hline Sex: Male & 0.8 \\
\hline Indication: Recanalization & -1 \\
\hline Side-branch artery: Yes & -1.1 \\
\hline Aneurysm's diameter (mm): > 8.9 & -1.1 \\
\hline Parent artery diameters ratio (PDR): > 1.3 & -0.8 \\
\hline Neck ratio (NR): > $1.1 ; 1.8 \leq$ & -0.4 \\
\hline Neck ratio (NR): > 1.8 & 0.2 \\
\hline Convexity of the parent artery & -0.2 \\
\hline Threshold (under = predictive of failure) & 0.75 \\
\hline
\end{tabular}

\begin{tabular}{|c|l|l|l|c|c|c|}
\hline LASSO & Accuracy & Sensitivity & Specificity & $\begin{array}{c}\text { Positive } \\
\text { Predictive } \\
\text { Value } \\
\text { (PPV) }\end{array}$ & $\begin{array}{c}\text { Negative } \\
\text { Predictive } \\
\text { Value } \\
\text { (NPV) }\end{array}$ & $\begin{array}{c}\text { Balanced } \\
\text { Accuracy }\end{array}$ \\
\hline $\begin{array}{c}\text { Training } \\
\text { sample }\end{array}$ & $\begin{array}{l}0.8725 \\
95 \% \mathrm{CI}: \\
(0.7919, \\
0.9304)\end{array}$ & 0.8875 & 0.8182 & 0.9467 & 0.6667 & 0.8528 \\
\hline Test sample & $\begin{array}{l}0.7885 \\
95 \% \mathrm{CI}: \\
(0.653, \\
0.8894)\end{array}$ & 0.9189 & 0.4667 & 0.8095 & 0.7000 & 0.6928 \\
\hline
\end{tabular}


Simplified version of the DIANES score:

\begin{tabular}{|r|c|}
\hline Component & Score \\
\hline 1. Sex & \\
\hline Male & 2 \\
\hline Female & -2 \\
\hline Indication & 2 \\
\hline First treatment & -2 \\
\hline Recanalization & \\
\hline Side-branch artery & 3 \\
\hline No & -3 \\
\hline $4 . \quad$ Aneurysm's diameter (mm) & \\
\hline$\leq 8.9$ & 2 \\
\hline$>8.9$ & -2 \\
\hline $5 . \quad$ Neck ratio (NR) & 1 \\
\hline$\leq 1.1$ & -1 \\
\hline$>1.1 ; 1.8 \leq$ & 1 \\
\hline$>1.8$ & 2 \\
\hline Parent artery diameters ratio (PDR) & -2 \\
\hline$>1.3$ & -1 \\
\hline$>1.3$ & \\
\hline Threshold (under = predictive of failure) & \\
\hline
\end{tabular}

\begin{tabular}{|c|c|c|c|c|c|c|}
\hline $\begin{array}{c}\text { Simplified } \\
\text { DIANES score }\end{array}$ & Accuracy & Sensitivity & Specificity & $\begin{array}{c}\text { Positive } \\
\text { Predictive } \\
\text { Value } \\
(\text { PPV })\end{array}$ & $\begin{array}{c}\text { Negative } \\
\text { Predictive } \\
\text { Value } \\
(\mathrm{NPV})\end{array}$ & AUC \\
\hline $\begin{array}{c}\text { Training } \\
\text { sample }\end{array}$ & $\begin{array}{c}0.87(0.80 \\
-0.94)\end{array}$ & $\begin{array}{c}0.91(0.84- \\
0.96)[73 / \\
80]\end{array}$ & $\begin{array}{c}0.72(0.52- \\
0.91)[16 / \\
22]\end{array}$ & $\begin{array}{c}0.92(0.86 \\
-0.98)[73 \\
/ 79]\end{array}$ & $\begin{array}{c}0.69(0.5- \\
0.88)[16 / \\
23]\end{array}$ & $\begin{array}{c}0.88 \\
(0.80- \\
0.97)\end{array}$ \\
\hline Test sample & $\begin{array}{c}0.77(0.65 \\
-0.89)\end{array}$ & $\begin{array}{c}0.92(0.82-[34 / 37] \\
1)\end{array}$ & $\begin{array}{c}0.40(0.59- \\
0.66)[6 / \\
15]\end{array}$ & $\begin{array}{c}0.79(0.66 \\
-0.91)[34 \\
/ 43]\end{array}$ & $\begin{array}{c}0.67(0.33 \\
-1)[6 / 9]\end{array}$ & $\begin{array}{c}0.70 \\
(0.52- \\
0.89)\end{array}$ \\
\hline Whole cohort & $0.84(0.77$ & $0.91(0.86-$ & $0.60(0.41-$ & $0.88(0.81$ \\
& $-0.90)$ & $\begin{array}{c}0.67)[107 / \\
117]\end{array}$ & $\begin{array}{c}0.75)[22 / \\
37]\end{array}$ & $\begin{array}{c}0.69(0.54) \\
{[107 / 122]}\end{array}$ & $\begin{array}{c}-0.85)[22 \\
/ 32]\end{array}$ & $\begin{array}{c}0.82 \\
(0.73- \\
0.91)\end{array}$ \\
\hline
\end{tabular}



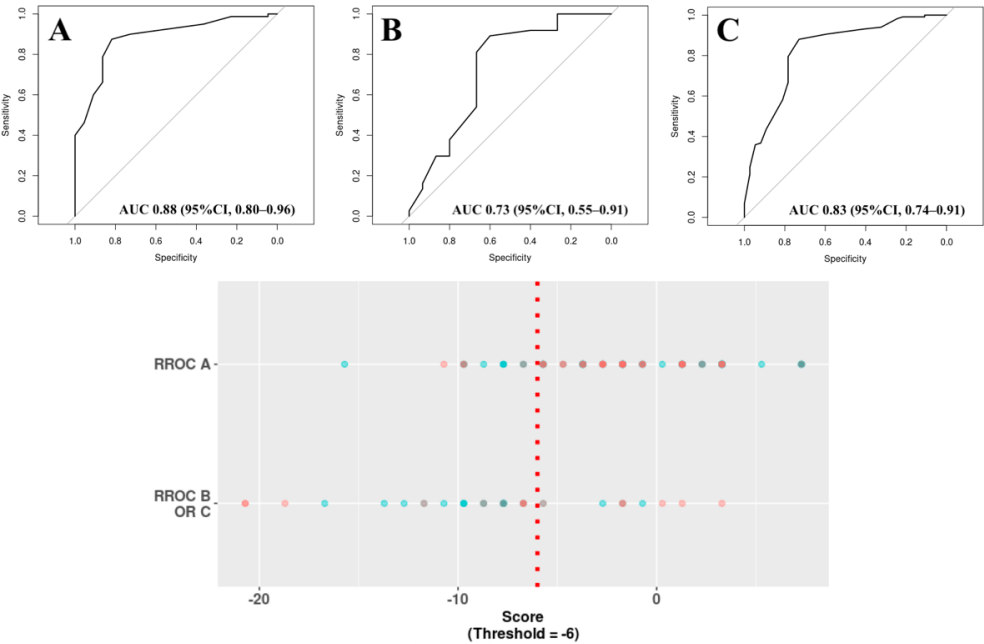